\title{
Case Report \\ Persistent Hyperprolactinemia and Bilateral Galactocele in a Male Infant
}

\author{
Paolo A. Tomasi, ${ }^{1,2}$ Giuseppe Fanciulli, ${ }^{1}$ Tiziana Casti, $^{3}$ and Giuseppe Delitala ${ }^{1}$ \\ ${ }^{1}$ Dipartimento-Struttura Clinica Medica-Patologia Speciale Medica, Università degli Studi di Sassari, \\ Viale San Pietro 8, 07100 Sassari, Italy \\ ${ }^{2}$ European Medicines Agency (EMEA), 7 Westferry Circus, London E14 4HB, UK \\ ${ }^{3}$ Pediatric Outpatients Clinic, AUSL 2, 07020 Buddusò, Italy
}

Correspondence should be addressed to Paolo A. Tomasi, paolo.tomasi@emea.europa.eu

Received 21 November 2008; Accepted 27 January 2009

Recommended by Filiz Mine Cizmecioglu

Galactocele is a benign breast lesion, usually occurring in nursing women. This lesion is a rare cause of breast enlargement in children. In this paper we describe the case of an infant with hyperprolactinemia (which persisted throughout 15 years of clinical observation) and bilateral galactocele. We speculate that a congenital midline defect in our patient might have impaired the normal dopaminergic inhibitory tone on pituitary lactotroph cells, thus leading to an increased prolactin secretion by the pituitary gland; this, in turn, might have favored the development of the galactocele.

Copyright (C) 2009 Paolo A. Tomasi et al. This is an open access article distributed under the Creative Commons Attribution License, which permits unrestricted use, distribution, and reproduction in any medium, provided the original work is properly cited.

Galactocele is a rare breast cyst containing milk-like material, usually observed in lactating women. This condition is rare in infants: only a handful of cases have been described [1-3]. Hyperprolactinemia is rare in children of less than 5 years; in particular, persistent isolated Prolactin (PRL) hypersecretion has never been described in infants.

Here, we describe a child who, to our knowledge, is the first infant with persistent isolated hyperprolactinemia and the concomitant presence of bilateral galactocele.

The child was born after caesarean section, performed at 34 weeks of gestation for both polyhydramnios and a previous caesarean delivery. Prenatal sonographic measurements and neonatal values were all around the 90th percentile. Perinatal anoxia led to admission to the neonatal intensive care unit. At physical examination, multiple congenital anomalies were present facial dysmorphism, low implant of the ears, hyperthelorism, macroglossia, a cleft soft palate, hyporeactivity, hypotonicity, muscular hypertrophy, membranous syndactily between the third and fourth left fingers. No skeletal abnormalities were present except for a relative hypoplasia of the facial bones. Electrolytes, thyroid hormones, creatine kinase, and lactate dehydrogenase values were normal. A normal $46 \mathrm{XY}$ karyotype was present. A transbregmatic cerebral sonography and an abdominal sonography did not show any abnormality. No abnormality was found by an ophthalmologic consultant. At 6 months a veloplastic repair was performed for correction of the cleft palate. At 8 months a large left inguinal hernia was diagnosed, and surgery was performed soon thereafter. At nine months a complete sonographic examination revealed no abnormalities in the brain, abdomen, or heart. At 12 months of age a small, soft, nontender, nonerythematous mass was observed below the left nipple. At 18 months the left areolar mass appeared increased, and a similar, although tender, lesion was apparent also in the right breast. Sonography showed that both lesions were of cystic nature. These findings prompted a thorough endocrinological evaluation of the child. Basal GH value was $4.68 \mathrm{ng} / \mathrm{mL}$, and IGF-I was within the normal range. PRL basal values at 0,30 , and 60 minutes after insertion of a forearm cannula were $94.8,98.8$, and $87.71 \mathrm{ng} / \mathrm{mL}$, respectively. After intravenous coadministration of TRH $50 \mu \mathrm{g}$, GnRH $25 \mu \mathrm{g}$, and GHRH $25 \mu \mathrm{g}$, TSH response was normal, PRL levels were more than $200 \mathrm{ng} / \mathrm{mL}$, and GH levels responded significantly, with a peak of $>50 \mathrm{ng} / \mathrm{mL}$. Gonadotropin release showed a postpubertal pattern, with a greater increase of $\mathrm{LH}$ than $\mathrm{FSH}$, which was inappropriate for 
the age of the boy. Other hormonal levels (including thyroid hormones, 17-hydroxyprogesterone, testosterone, estradiol, DHEAS, cortisol, and ACTH) were all within normal limits. Magnetic resonance imaging (MRI) of the brain, performed at 24 months, was normal. Scrotal echography and repeated sonographic examinations of upper abdomen were again negative. Sonography of the mammary cysts consistently showed a hypoechoic lesion with smooth margins, of $3.5 \mathrm{~cm}$ and $1 \mathrm{~cm}$ diameter in the left and right nipples, respectively. The left cyst was aspirated at 26 months, yielding approximately $18 \mathrm{~mL}$ of a whitish, milk-like material. Cytological analysis showed very rare histiocytes and lymphocytes. Lactose and casein were also present in the fluid. The left cyst did not reform initially, and the right one was stable. Bone age at 2.9 years, measured by the Tanner-Whitehouse TWII method, was 3.5 years. Basal GH and IGF-I levels at the same age were normal. At 5.5 years, PRL levels basal values remained elevated. They showed an increased after TRH, from 40.5 to $69.7 \mathrm{ng} / \mathrm{mL}$, and after metoclopramide, from 36.0 to $128.0 \mathrm{ng} / \mathrm{mL}$. A repeat $\mathrm{GnRH}$ test again displayed a postpubertal pattern of gonadotropin response. The left cyst gradually reformed, and the right one was of larger volume in a sonography performed at 6.5 years. For this reason, bilateral surgical excision was performed at 7 years. The cysts were easily isolated and were removed intact. Histological examination revealed a double-layered epithelium-covered cyst, with areas of papillary hyperplasia, containing amorphous material; pericystic inflammation was present, with a marked histyoid component. The postoperative recovery was uneventful, with no reappearance of the lesions, both clinically and sonographically. Throughout years 6 to 13, a tendency toward a lowering (but not a normalization) of the PRL levels became apparent. However, PRL rose again with the onset of puberty (at 14 years: $38 \mathrm{ng} / \mathrm{mL}$ ). Thyroid and adrenal function tests were always in the normal range. A second MRI of the pituitary region showed again no abnormalities. A final MRI scan of the brain, performed at 16 years of age, was normal. At the last followup visit (age 16.5), the patient's height was $176 \mathrm{~cm}\left(60^{\circ}\right.$ percentile), versus a genetic target of $170 \mathrm{~cm}\left(25^{\circ}\right)$; there was no residual galactocele. His Tanner stage was defined as G4P4. Testes were $15 \mathrm{~mL}$ (right) and $10 \mathrm{~mL}$ (left). Scrotal ultrasound showed a mild right hydrocele, with a severe left varicocele, with microcalcifications.

In our child, three syndromes were evaluated in the differential diagnosis, to try to account for the complex clinical picture. Beckwith-Wiedemann syndrome was ruled out because of the absence of hypoglycemia, omphalocele and visceromegaly. Sotos syndrome was considered highly unlikely because of the lack of classical brain MRI presentation (ventricular dilatation, prominence of the trigone, prominence of the occipital horns). In addition, since our patient shared some of the features of the Simpson-GolabiBehmel syndrome, we carried out a mutation analysis of the associated Glypican-3 gene, but no mutations were detected.

This patient attracted our interested for two reasons: because of the bilateral galactocele, a rare condition by itself, and because of the persistent isolated hyperprolactinemia displayed by the child throughout more than 15 years of followup.

The etiology of hyperprolactinemia in this subject is unclear. Hyperprolactinemia in children has been described in association with other conditions such as hypothyroidism [4] and celiac disease [5], or with the presence of macroprolactin [6]. These conditions were excluded in our patient. Moreover, since plasma PRL levels remained high after surgical removal of the bilateral cysts, local pressure effects were probably not the cause of the hyperprolactinemia. The normal responses of PRL to the TRH and metoclopramide stimulation tests play upon central (hypothalamus-pituitary) origin of the hypersecretion. A pituitary adenoma is unlikely, since repeated MRI of the brain never showed signs of a mass. The normal IGF-I levels and the lack of a consistent GH hypersecretion constitutes evidence against a mammosomatotroph hyperplasia.

The etiology of galactocele is still unknown. Since this lesion is mainly noted in lactating women, PRL has been suspected to play a role, although obstruction of a galactophore is clearly the most important pathogenetic mechanism.

We speculate that a midline defect in our patient might have impaired the tubero-infundibular dopaminergic tract, thus leading to a diminished tonic inhibition of PRL secretion by the pituitary gland. This, in turn, might have favored the development of the galactocele.

\section{References}

[1] M. Boyle, K. Lakhoo, and P. Ramani, "Galactocele in a male infant: case report and review of literature," Fetal and Pediatric Pathology, vol. 13, no. 3, pp. 305-308, 1993.

[2] Y. Cesur, H. Caksen, I. Demirtaş, M. Kösem, A. Uner, and R. Ozer, "Bilateral galactocele in a male infant: a rare cause of gynecomastia in childhood," Journal of Pediatric Endocrinology \& Metabolism, vol. 14, no. 1, pp. 107-109, 2001.

[3] N. Rahman, M. Davenport, and C. Buchanan, "Galactocele in a male infant with congenital hypopituitarism," Journal of Pediatric Endocrinology \& Metabolism, vol. 17, no. 10, pp. 14511453, 2004.

[4] M. Kocova, S. Netkov, and F. Sukarova-Angelovska, "Pituitary pseudotumor with unusual presentation reversed shortly after the introduction of thyroxine replacement therapy," Journal of Pediatric Endocrinology \& Metabolism, vol. 14, no. 9, pp. 16651669, 2001.

[5] R. Reifen, D. Buskila, M. Maislos, J. Press, and A. Lerner, "Serum prolactin in coeliac disease: a marker for disease activity," Archives of Disease in Childhood, vol. 77, no. 2, pp. 155-157, 1997.

[6] H. L. Fideleff, G. Ruibal, H. Boquete, A. Pujol, A. Sequera, and P. Sobrado, "Macroprolactinemia in childhood and adolescence: a cause of asymptomatic hyperprolactinemia," Hormone Research, vol. 53, no. 1, pp. 16-19, 2000. 